\title{
Cognitive Strategy-Specific Increases in Phosphorylated cAMP Response Element-Binding Protein and c-Fos in the Hippocampus and Dorsal Striatum
}

\author{
Paul J. Colombo, ${ }^{1,2}$ Jennifer J. Brightwell, ${ }^{1}$ and Renee A. Countryman ${ }^{2}$ \\ ${ }^{1}$ Neuroscience Program and ${ }^{2}$ Department of Psychology, Tulane University, New Orleans, Louisiana 70118
}

\begin{abstract}
Extensive research has shown that the hippocampus and striatum have dissociable roles in memory and are necessary for "place" and "response" learning, respectively. In the present study, rats were trained on a cross maze task that could be solved by either a place or a response strategy, and the strategy used was determined by a probe trial. Phosphorylated cAMP response element-binding protein (pCREB) and c-Fos immunoreactivity (IR) were measured in the hippocampus and striatum either immediately or $1 \mathrm{hr}$ after cross maze training. Immediately after training, pCREB-IR and c-Fos-IR were significantly higher in the hippocampus and striatum of trained rats than in control rats matched for motor activity, but the increase was independent of the strategy revealed at probe. One hour after training, however, pCREB-IR and c-Fos-IR were sustained in the hippocampal pyramidal and granule cell layers of place learners but returned to basal levels among response learners. In addition, PCREB-IR was sustained in the dorsomedial and dorsolateral striatum of response learners but returned to basal levels among place learners. There were no differences between place and response learners in c-Fos-IR in the striatum at either time point. The present results indicate that cross maze training causes an initial activation of transcription factors in both the hippocampus and striatum. Formation of memory for a place strategy, however, is related to sustained phosphorylation of CREB and expression of c-Fos for at least $1 \mathrm{hr}$ in the hippocampus, whereas formation of memory for a response strategy is related to phosphorylation of CREB in the striatum.
\end{abstract}

Key words: cAMP response element-binding protein; CREB; c-Fos; place learning; response learning; hippocampus; dorsal neostriatum; cross maze

\section{Introduction}

Distinct memory functions are attributed to the hippocampal formation and the neostriatum in humans (Knowlton et al., 1996; Maguire et al., 1998; Casey et al., 2002), nonhuman primates (Teng et al., 2000; Fernandez-Ruiz et al., 2001), and rats (Kesner and Beers, 1988; Kesner et al., 1993; McDonald and White, 1993; Packard et al., 1994; Compton, 2001). Lesions or pharmacological manipulations that alter the function of the hippocampal formation or the neostriatum provide the primary evidence that these two brain systems are specialized for different types of memory. In rats, damage to the hippocampal formation selectively impairs formation of memory for the relationships among stimuli (Eichenbaum et al., 1990; Eichenbaum, 2001), whereas damage to the neostriatum tends to impair acquisition of associations between stimuli and motor responses (Colombo et al., 1989; Packard and White, 1990; Packard and McGaugh, 1992; McDonald and White, 1994; Golf Racht-Delatour and El Massioui, 1999). Specialized mnemonic functions attributed to the hippocampus and striatum, respectively, include memory for spatial and nonspatial information (Packard and McGaugh, 1992, 1996), memory for allocentric (place) and egocentric (response) information (Kesner and Beers, 1988; Packard, 1999),

Received 0ct. 9, 2002; revised Feb. 4, 2003; accepted Feb. 7, 2003.

This work was supported by National Science Foundation Grant IBN-0133734.

Correspondence should be addressed to Paul J. Colombo, Tulane University, Department of Psychology, New Orleans, LA 70118. E-mail: pcolomb@tulane.edu.

Copyright $\odot 2003$ Society for Neuroscience $\quad 0270-6474 / 03 / 233547-08 \$ 15.00 / 0$ and declarative and procedural memory (DeCoteau and Kesner, 2000). Although there is compelling evidence that the contributions of the hippocampus and striatum to memory formation can be dissociated, the relationship between the systems during normal operations is not understood. One recent report suggests that the two systems may operate in temporal sequence (Packard, 1999).

Members of the cAMP response element-binding protein (CREB) family of transcription factors have been implicated in the formation of long-term memory (Lamprecht and Dudai, 1996; Lamprecht et al., 1997). Suppression of CREB protein by administration of antisense oligodeoxynucleotides (Guzowski and McGaugh, 1997) or genetic knock-out (Bourtchuladze et al., 1994) impairs spatial memory, whereas overexpression of CREB can enhance the formation of long-term memory (Josselyn et al., 2001). CREB phosphorylation is increased by exposure to a novel environment (Vianna et al., 2000), contextual fear conditioning (Stanciu et al., 2001), inhibitory avoidance (Bernabeu et al., 1997; Cammarota et al., 2000; Taubenfeld et al., 2001), and radial arm maze training (Mizuno et al., 2002). Stimuli that increase cAMP or $\mathrm{Ca}^{2+}$-dependent protein kinase activity phosphorylate CREB (Gonzalez and Montminy, 1989; Dash et al., 1991), and phosphorylated CREB (pCREB) stimulates the expression of immediate-early genes, including the transcription factor c-Fos (Sheng and Greenberg, 1990). Learning-induced expression of c-Fos is implicated in visual recognition memory (Wan et al., 1999), fear conditioning (Milanovic et al., 1998; Radulovic et al., 1998), spatial working (Vann et al., 2000) and reference memory 


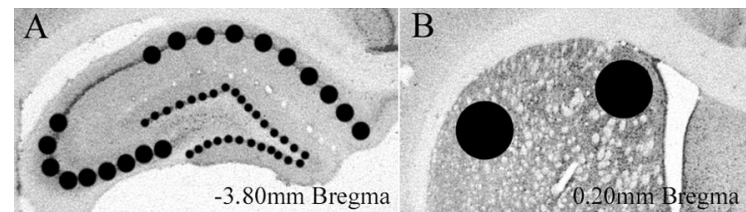

Figure 1. A, Immunoreactive cells were counted within sampled areas of the dorsal hippocampus. These included the pyramidal cell layers CA1 and CA3 (medium circles) and the granule cell layers of the dentate gyrus (small circles). $B$, Sampled areas of the dorsomedial and dorsolateral striatum (large circles).

(Qiang et al., 1999), brightness discrimination (Tischmeyer et al., 1990), and avoidance learning (Qiang et al., 1999; Cammarota et al., 2000).

In the present study, rats were trained on a cross maze task that could be solved by either a hippocampus-dependent place strategy or a dorsal striatum-dependent response strategy, and the strategy used was determined during a probe trial. Levels of pCREB and c-Fos immunoreactivity (IR) were measured in the hippocampus and striatum either immediately or $1 \mathrm{hr}$ after cross maze training.

\section{Materials and Methods}

Eighty-two naive male Long-Evans hooded rats (weight, 250-275 gm) were housed individually in a temperature-controlled environment with a $12 \mathrm{hr}$ light/dark cycle (lights on at 7:00 A.M.) and ad libitum access to food and water. All behavioral testing was conducted during the light phase of the cycle.

The behavioral apparatus was an eight arm radial maze (Lafayette Instruments, Lafayette, IN) with black metal floors and clear Plexiglas walls. The arms of the cross maze $(10 \mathrm{~cm}$ wide $\times 70 \mathrm{~cm}$ long $\times 20 \mathrm{~cm}$ high) had recessed food wells at the end and were separated from an octagonal center compartment $(33 \mathrm{~cm})$. The maze was located in a testing room that contained several extramaze cues and was sanitized between rats and before all probe trials to inhibit intramaze olfactory cues.

Animals were handled extensively $(5 \mathrm{~min}$ each per day) for 2 weeks from the time of arrival to the first day of habituation. One week before maze testing, animals were reduced to $85 \%$ of their free-feeding weights over $7 \mathrm{~d}$ and maintained at this weight throughout the experiment. One day before habituation, animals received 4 gm of Froot Loops cereal (Kellogg, Battle Creek, MI) in addition to sufficient chow to maintain the $85 \%$ target weight and reduce neophobic reactions to the Froot Loops during training trials.

Animals were habituated for $3 \mathrm{~d}$ with one 5 min trial per day. On day 1 , the rats were placed into the south arm of the maze with two additional arms open at right angles (west and east) and with Froot Loops broken into thirds and scattered throughout all three arms. On day 2, the Froot Loops were placed only in the east and west arms of the maze, and on day 3, the Froot Loops were placed only in the recessed food wells at the ends of the east and west arms. Training and testing were completed on the fourth day. Rats were released from the end of the south arm and allowed to enter one arm (neither of which was baited), and the arm op-

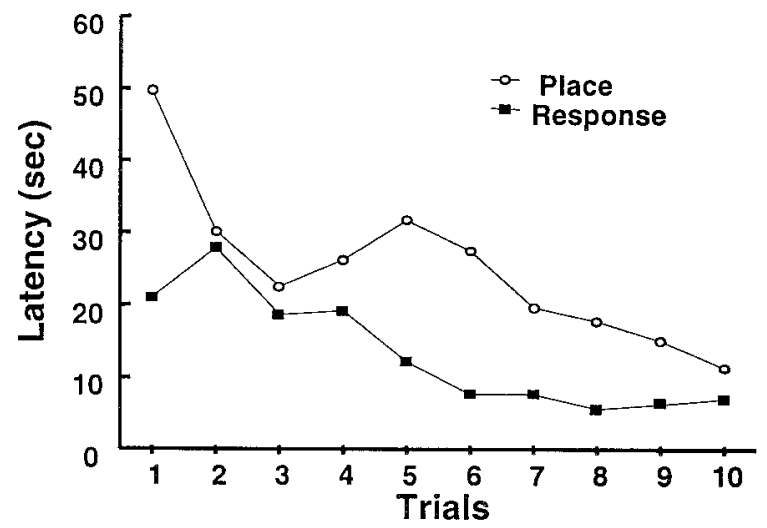

Figure 2. Latency to complete the last 10 criterion trials for place learners $(n=27)$ and response learners $(n=23)$.

posite the one chosen was baited for all subsequent trials. On training trials, rats were allowed 2 min to obtain the food reward of one-third of a Froot Loop. Entries into the unbaited arm of the maze were scored as incorrect responses, and entries into the baited arm of the maze were scored as correct responses. An entry was defined as all four feet crossing into an arm, and rats were allowed to enter one arm only per trial, after which they were placed back into their holding cage for a $30 \mathrm{sec}$ intertrial interval. All rats were trained to a criterion of 9 of 10 correct choices (range, 11-44 trials), after which they were released from the arm opposite the original start location (north) for a single probe trial. Rats that reentered the arm rewarded during training were categorized as place learners, whereas rats that made the same turning response as that re-
A
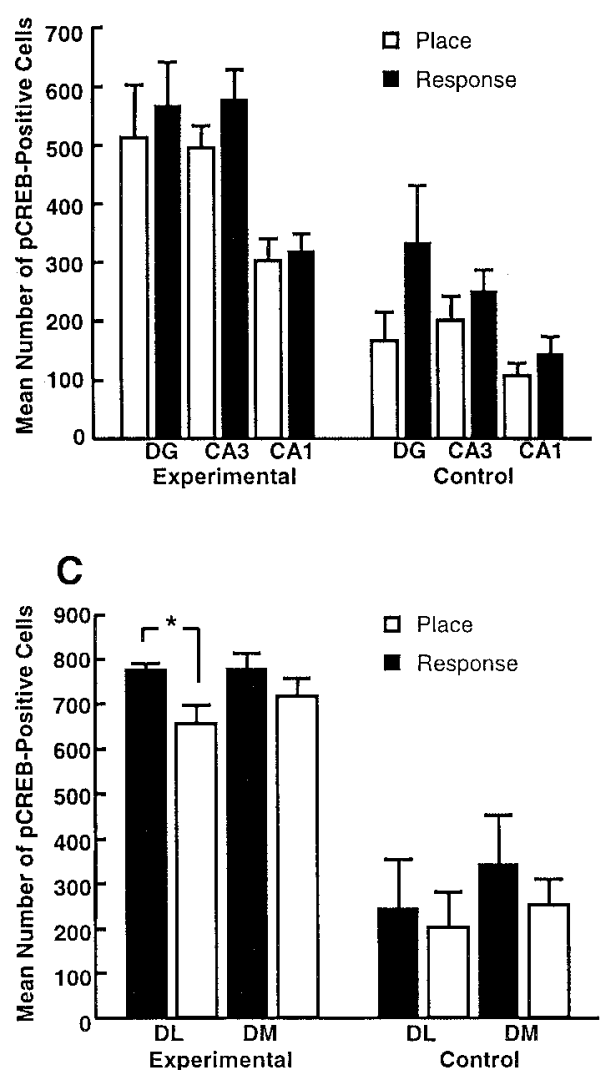

B

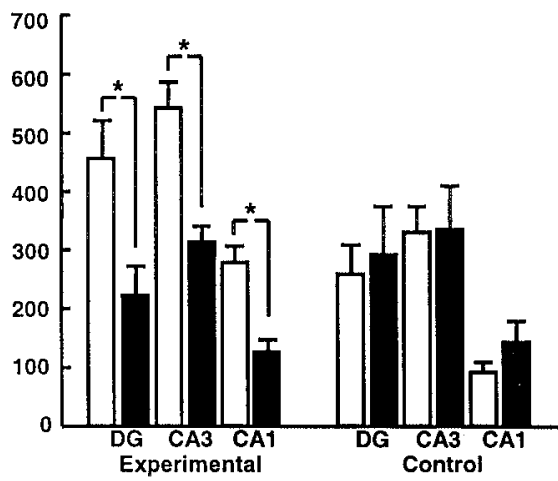

Figure 3. Numbers of $p C R E B$-positive cells in the hippocampus $(A, B)$ and striatum $(C, D)$ of place learners, response learners, and controls matched to the number and duration of trials of place and response learners either immediately $(A, C)$ or $1 \mathrm{hr}(B, D)$ after completion of training. DG, Dentate gyrus; DL, dorsolateral striatum; DM, dorsomedial striatum. ${ }^{*} p<0.05$. 

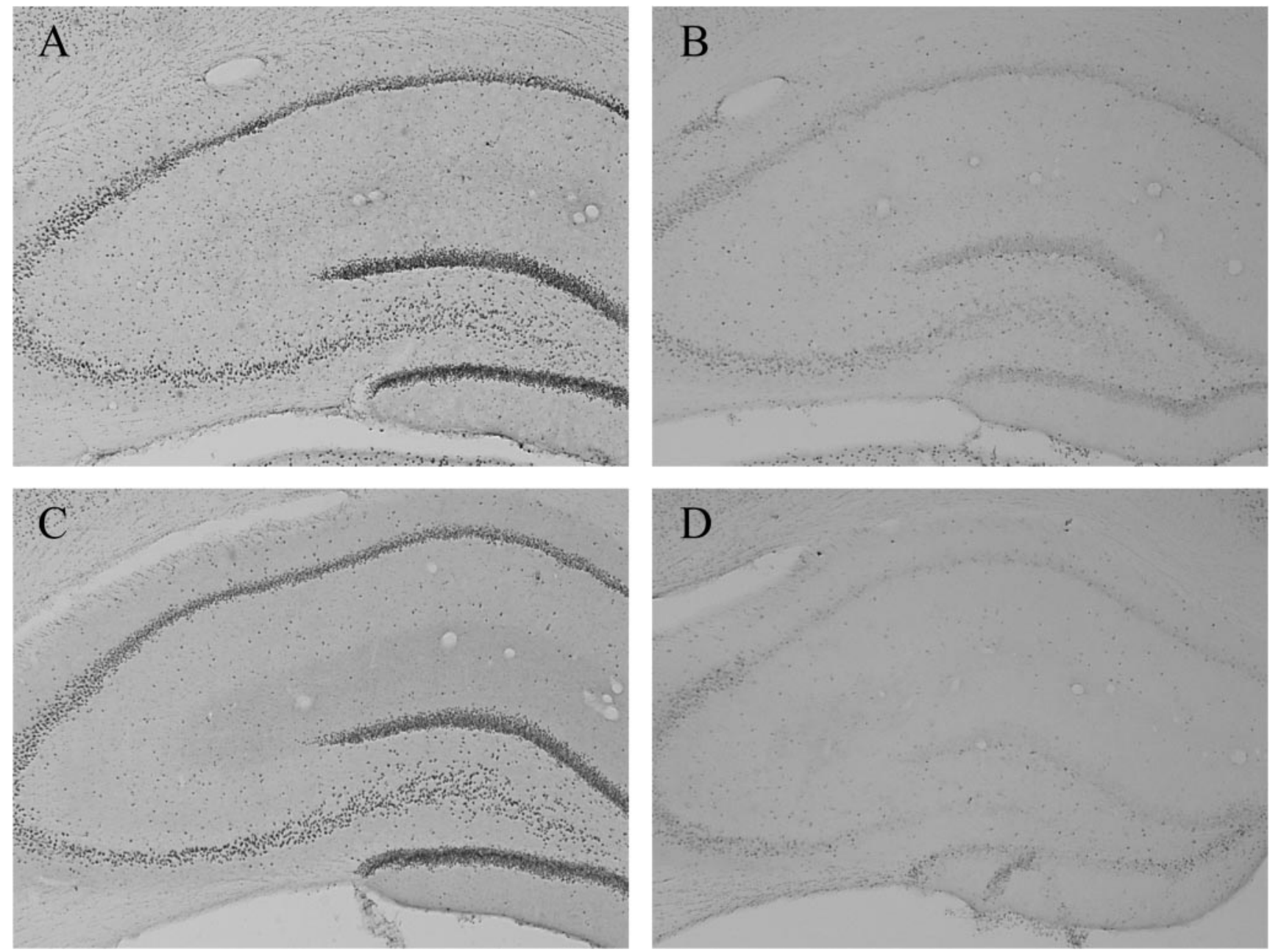

Figure 4. $A, p C R E B-I R$ in the hippocampus of a representative place learner immediately after training. $B, p C R E B-I R$ in the hippocampus of a representative motor control immediately after training. pCREB-IR in the hippocampus of a representative response learner immediately $(C)$ and $1 \mathrm{hr}(D)$ after training.

warded during training and thus entered the arm opposite the one rewarded during training were categorized as response learners. Previous research (Restle, 1957; Packard, 1999) and pilot studies conducted in this laboratory (data not shown) indicate that factors such as the amount of training, salience of extramaze cues, and amount of illumination influence the numbers of rats characterized as place and response learners based on performance during the probe trial. In the present study, probe trials revealed that approximately one-half of the trained rats used a place strategy $(n=27)$ and one-half used a response strategy $(n=23)$. Rats in control conditions were matched to the numbers and durations of trials of both place $(n=16)$ and response $(n=16)$ learners. This group was included to test whether differences in PCREB or c-Fos between place and response learners were attributable to differences in cognitive factors or to differences in locomotor or other performance factors. Control rats were released from the south arm on all trials and could access the north arm only, whereas experimental rats were released from the south arm on all trials except the probe trial. Thus, control rats were matched to experimental rats in all aspects of the task except that they had only one arm available for food reward, whereas experimental rats had to choose between two.

Either immediately or $1 \mathrm{hr}$ after the probe trial, animals were injected with a ketamine-xylazine solution $(1.65 \mathrm{mg} / \mathrm{kg})$ and perfused transcardially with ice-cold $0.1 \mathrm{M}$ PBS, pH 7.4, and $\mathrm{NaNO}_{3}$ followed by ice-cold $4 \%$ paraformaldehyde in $0.1 \mathrm{~m}$ PBS. Brains were removed and postfixed in $4 \%$ paraformaldehyde for $3 \mathrm{hr}$ and then transferred to a $20 \%$ sucrose and $0.1 \mathrm{~m}$ phosphate buffer cryoprotectant overnight at $4^{\circ} \mathrm{C}$. Forty micrometer coronal sections were taken beginning at the posterior end of the anterior olfactory nucleus and extending throughout the hippocampus. Sections were collected in cryopreservative and frozen at $-70^{\circ} \mathrm{C}$. For each subject, four sections were selected at approximately bregma 0.2 $\mathrm{mm}$ for striatum and four sections at bregma $-3.8 \mathrm{~mm}$ for the hippocampus (Fig. 1) and immunostained as described below. Net wells (24 $\mathrm{mm}$; Corning, Corning, NY) were used to wash tissue sections several times in $0.05 \mathrm{M}$ PBS and then once in $1 \%$ normal goat serum (NGS), $0.02 \%$ Triton X-100 (TX), and $1 \% \mathrm{H}_{2} \mathrm{O}_{2}$ in PBS for 10 min to inhibit endogenous peroxidase. Sections were blocked for $15 \mathrm{~min}$ in a $2 \%$ NGS and $0.4 \%$ TX solution in PBS followed by incubation in 1\% NGS and $0.4 \%$ TX in PBS containing either c-Fos rabbit polyclonal antibody (1: 10,000; Santa Cruz Biotechnology, Santa Cruz, CA) or pCREB rabbit polyclonal antibody (1:1000; Upstate Biotechnology, Lake Placid, NY) for $48 \mathrm{hr}$ at $4^{\circ} \mathrm{C}$. Sections were washed four times with $0.05 \mathrm{M}$ PBS for 15 min each before a $1 \mathrm{hr}$ incubation in biotinylated goat anti-rabbit secondary antibody (1:400 in 1\% NGS and 0.2\% TX PBS; Santa Cruz Biotechnology). Sections were washed in 0.05 м PBS three times for 5 min each and then processed with avidin-biotinylated horseradish peroxidase complex in PBS (Elite Kit; Vector Laboratories, Burlingame, CA) for 45 $\mathrm{min}$ at room temperature. Sections were washed four times for $15 \mathrm{~min}$ each in PBS, and the reaction was visualized with diaminobenzidine (DAB substrate kit; Vector Laboratories). The reaction was stopped by washing three times for $10 \mathrm{~min}$ each in cold $0.01 \mathrm{M}$ PBS. Sections were mounted on slides, allowed to dry overnight, and plated under coverslips. Nuclear immunoreactivity was quantified by the two focal plane method of Brown et al. (1998). Sampling templates of consistent area were established, and immunoreactive cells were counted in CA1, CA3, 

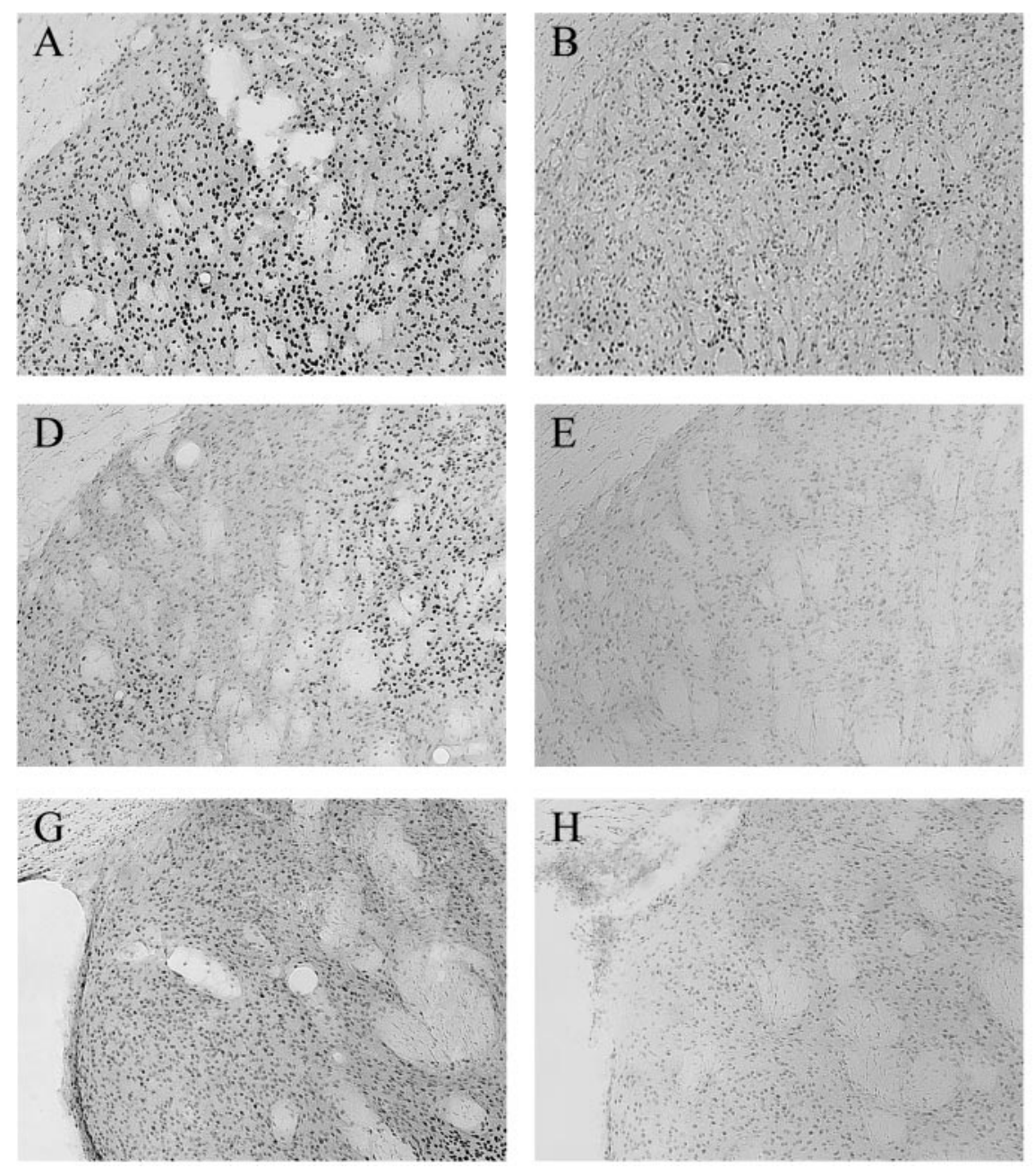
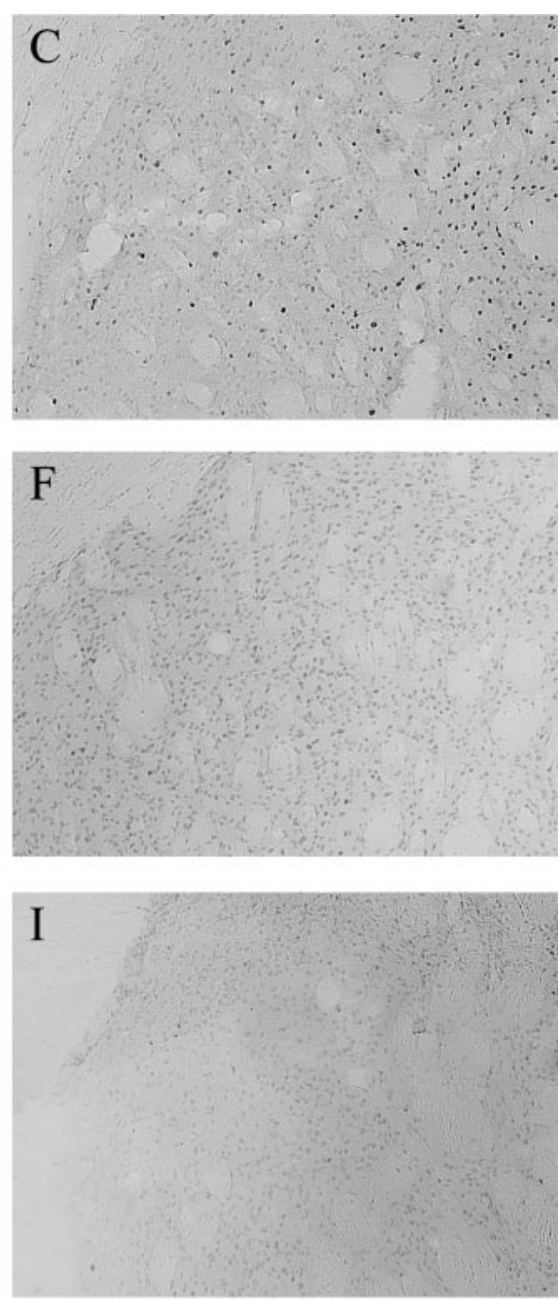

Figure 5. Representative $p C R E B-I R$ immediately after training in the dorsolateral striatum of a response learner $(A)$, place learner $(B)$, and motor control ( $C$. Representative $p C R E B-I R 1 \mathrm{hr}$ after training in the dorsolateral striatum of a response learner $(D)$, place learner $(E)$, and motor control $(F)$. Representative $p C R E B-I R 1 \mathrm{hr}$ after training in the dorsomedial striatum of a response learner $(G)$, place learner $(H)$, and motor control $(I)$.

and the dentate gyrus of the dorsal hippocampus, as well as the dorsomedial and dorsolateral striatum (Fig. 1).

\section{Results}

ANOVA revealed no difference in the number of trials to criterion between place and response learners $\left(F_{(1,48)}=0.01 ; p=\right.$ $0.92)$. The mean number of trials to criterion was $18.9 \pm 1.1 \mathrm{SEM}$ for place learners and $18.7 \pm 1.7$ SEM for response learners. In contrast, the total time in the maze and the average trial duration over the last 10 criterion trials were greater among place learners than among response learners $\left(F_{(1,48)}=6.86, p=0.01\right.$ and $F_{(1,48)}=7.83, p=0.007$, respectively) (Fig. 2).

Relationships between learning and levels of pCREB-IR and c-Fos-IR were analyzed independently for the hippocampus and striatum. Multivariate ANOVAs (MANOVAs) were conducted with levels of pCREB-IR and c-Fos-IR in CA1, CA3, and the dentate gyrus of the hippocampus and dorsomedial and dorsolateral striatum as dependent variables. Independent variables were training condition (trained or control), type of strategy revealed at probe test (place or response), and interval between test and killing of the animal (immediate or $1 \mathrm{hr}$ ).

Overall MANOVA of pCREB in the hippocampus revealed significant main effects for training condition $\left(F_{(3,71)}=20.4 ; p<\right.$ $0.001)$, test-to-killing interval $\left(F_{(3,71)}=2.96 ; p=0.04\right)$, and a training condition by test-to-killing interval interaction $\left(F_{(3,71)}=\right.$ $3.92 ; p=0.01$ ) (Figs. $3 A, B, 4)$. Overall ANOVA of pCREB in the striatum revealed significant main effects for training condition $\left(F_{(2,71)}=37.6 ; p<0.001\right)$, test-to-killing interval $\left(F_{(2,71)}=60.2\right.$; $p<0.001)$, and a training condition by test-to-killing interval interaction $\left(F_{(2,71)}=28.7 ; p<0.001\right)$ (Figs. 3C,D, 5). Thus, trained rats had significantly more hippocampal and striatal pCREB-IR than motor controls immediately after training, and that effect was independent of whether rats showed place or response strategies. One hour after training, however, levels of pCREB remained significantly greater in the hippocampus of place learners than in that of motor controls $\left(F_{(1,20)}=13.6 ; p=\right.$ 0.001 ), whereas there was no difference between levels of pCREB in the hippocampus of response learners compared with motor controls $\left(F_{(1,18)}=0.35 ; p=0.56\right)$ (Fig. $\left.3 B\right)$. Of particular importance, place learners had higher levels of hippocampal pCREB than response learners $1 \mathrm{hr}$ after training. These differences were found throughout the principal cell layers of the hippocampus and included the dentate gyrus $\left(F_{(1,24)}=7.8 ; p=0.01\right)$, CA1 $\left(F_{(1,24)}=17.9 ; p<0.001\right)$, and CA3 $\left(F_{(1,24)}=18.4 ; p<0.001\right)$. The converse pattern was found in the striatum $1 \mathrm{hr}$ after training. That is, levels of pCREB remained significantly greater in the striatum of response learners than in that of motor controls 
$\left(F_{(1,18)}=4.8 ; p=0.04\right)$, but there was no difference between levels of pCREB in the striatum of place learners and that of motor controls $\left(F_{(1,20)}=0.78 ; p=0.39\right)$ (Fig. $3 D)$. Response learners had significantly greater levels of $\mathrm{pCREB}$ than place learners in the dorsolateral striatum immediately $\left(F_{(1,21)}=6.1 ; p=0.02\right)$ and $1 \mathrm{hr}$ after training $\left(F_{(1,24)}=4.3 ; p=0.049\right)$ and in the dorsomedial striatum $\left(F_{(1,24)}=8.48\right.$; $p=0.008) 1 \mathrm{hr}$ after training (Fig. $3 C, D$ ).

Overall MANOVA of c-Fos in the hippocampus revealed a significant main effect of training condition $\left(F_{(3,63)}=73.8\right.$; $p<0.001)$. Thus, there was significantly more hippocampal c-Fos-IR in trained rats than in control rats immediately and 1 $\mathrm{hr}$ after training (Figs. $6 A, B, 7)$. In the striatum, overall ANOVA of c-Fos revealed a significant main effect of test-to-killing interval $\left(F_{(2,71)}=24.5 ; p<0.001\right)$ and a training condition by test-to-killing interval interaction $\left(F_{(2,71)}=6.67 ; p=0.002\right)$. Thus, there was greater c-Fos-IR immediately after training than $1 \mathrm{hr}$ after training. The training condition by test-to-killing interaction was attributable to greater c-Fos-IR among trained rats than among motor controls immediately after training $\left(F_{(2,37)}=5.88 ; p=0.006\right)$ but not $1 \mathrm{hr}$ after training (Fig. 6C,D). Place learners and response learners had equivalent levels of c-Fos-IR in the hippocampus immediately after training. At $1 \mathrm{hr}$ after training, however, place learners had significantly higher levels of c-Fos-IR in the dentate gyrus and CA1 than response learners $\left(F_{(1,24)}=4.3\right.$, $p=0.04$ and $F_{(1,24)}=4.9, p=0.01$, respectively) (Fig. 6B). There were no differences in striatal c-Fos-IR between place and response learners either immediately or $1 \mathrm{hr}$ after training (Figs. $6 C, D, 8)$. Representative images of pCREB and c-Fos immunoreactivity in the hippocampus and striatum of place learners, response learners, and controls are shown in Figures 4, 5, 7, and 8.

\section{Discussion}

The main findings of this study are twofold. First, rats trained to make a spatial discrimination in the cross maze have significantly more phosphorylation of CREB and expression of c-Fos in the hippocampus and striatum than control rats matched for motor activity and time in the maze. The activity of these transcription factors occurs initially in both the hippocampus and the striatum independently of whether rats use place or response strategies to solve the task. Second, regional activity of CREB, and to a lesser extent c-Fos, distinguishes place and response learners $1 \mathrm{hr}$ after training. Specifically, pCREB-IR is greater in the dentate gyrus, $\mathrm{CA} 1$, and $\mathrm{CA} 3$ of place learners than in that of response learners. In contrast, pCREB-IR is greater in the dorsolateral and dorsomedial striatum of response learners than in that of place learners. Elevated c-Fos is observed in the dentate gyrus and CA1 of place learners compared with response learners $1 \mathrm{hr}$ after training.

It is most likely that regional differences in pCREB and c-Fos between place and response learners are related to differences in cognitive factors rather than to differences in locomotor or other
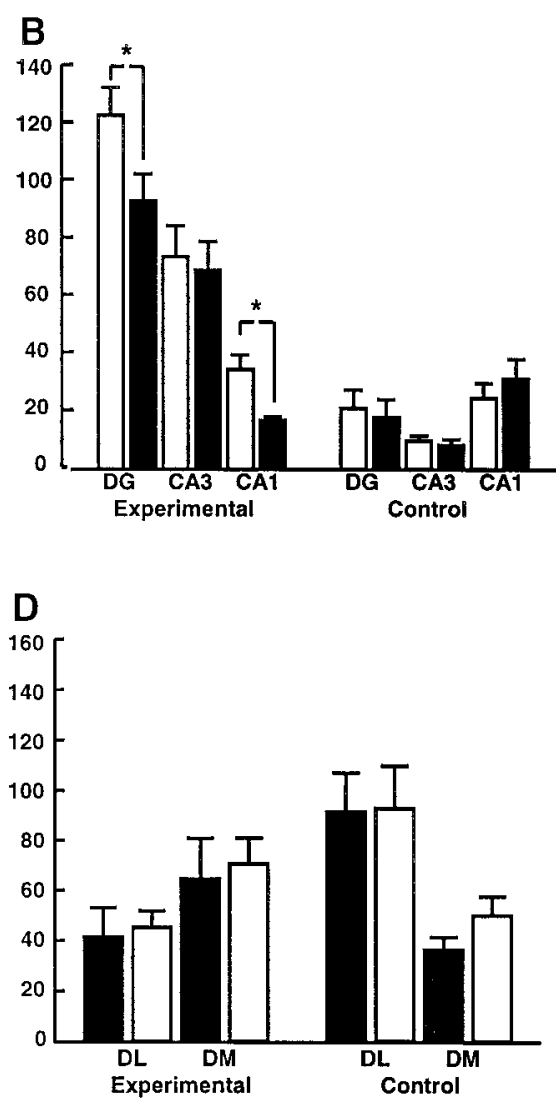

Figure 6. Numbers of $c$-Fos-positive cells in the hippocampus $(A, B)$ and striatum $(C, D)$ of place learners, response learners, and controls matched to the numbers and durations of trials of place and response learners either immediately $(A, C)$ or $1 \mathrm{hr}(B, D)$ after completion of training. DG, Dentate gyrus; DL, dorsolateral striatum; DM, dorsomedial striatum. ${ }^{*} p<0.05$.

performance factors. This conclusion is based on our finding that levels of pCREB and c-Fos do not differ in either the hippocampus or the striatum of control rats matched to the numbers and durations of trials of place learners in comparisons with controls matched to response learners. Thus, differences in the numbers and durations of trials in the range observed between place and response learners are not sufficient to cause the differences in pCREB and c-Fos that we report here.

The current findings extend previous dissociations of the hippocampus and striatum resulting from localized lesions (Packard and McGaugh, 1992; Kesner et al., 1993; McDonald and White, 1993) or pharmacological manipulations (Packard and White, 1990; Packard and Teather, 1997, 1998; Packard, 1999). Specifically, functional measures of transcription factors involved in memory formation reveal localized activity in the hippocampus of place learners and in the striatum of response learners.

White and McDonald (2002) theorized that multiple parallel memory systems including the hippocampus and dorsal striatum access much of the same information, but that each system has a unique "processing style." The present results are consistent with this theory in that activation of the transcription factors CREB and c-Fos was observed initially in both the hippocampus and striatum immediately after training. One hour after training, however, sustained activation of the transcription factors was observed only in the brain region implicated in a particular type of memory storage. Sustained pCREB and c-Fos were observed in the hippocampus of place learners but not response learners, whereas sustained pCREB occurs in the dorsal striatum of response learners but not place learners. 

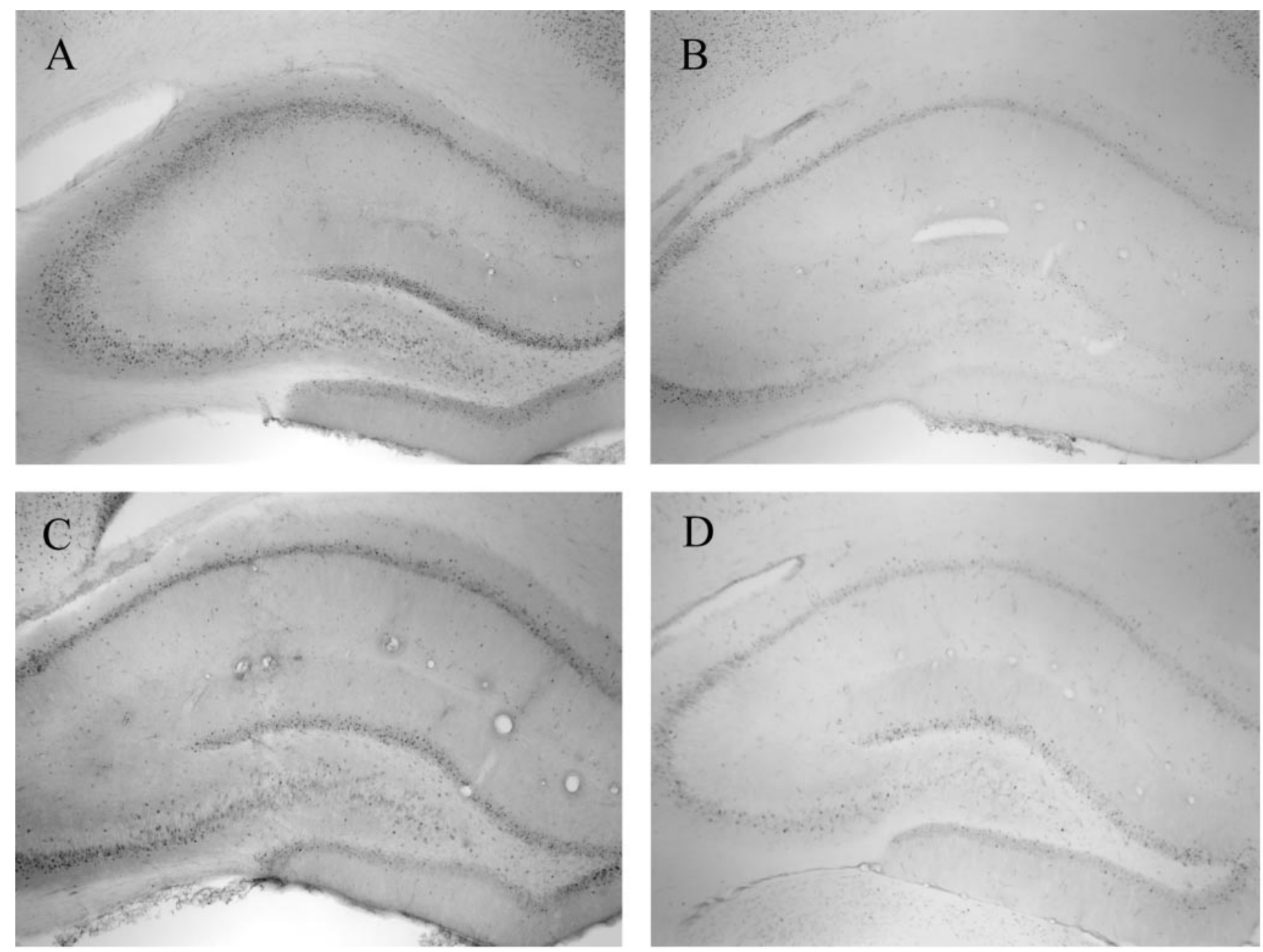

Figure 7. Representative c-Fos-IR immediately after training in the hippocampus of experimental $(A)$ and motor control $(B)$ rats. Representative c-Fos-IR 1 hr after training in the hippocampus of place learners $(C)$ and response learners $(D)$.

It has been proposed that the dorsomedial and dorsolateral striatum are involved primarily in stimulus-stimulus and stimulus-response associations, respectively (Devan and White, 1999; Devan et al., 1999; White and McDonald, 2002). Rats that adopted a response strategy had elevated pCREB in the dorsolateral striatum both immediately and $1 \mathrm{hr}$ after learning compared with place learners, which is consistent with the hypothesis that the dorsolateral striatum has a prominent role in coding stimulus-response associations. In contrast, there was no difference in pCREB between place and response learners in the dorsomedial striatum immediately after training. By $1 \mathrm{hr}$ after training, levels of pCREB in the dorsomedial striatum were significantly higher in response learners than in place learners. Thus, although the present findings indicate neuronal plasticity in the dorsolateral striatum during response learning, they do not support a prominent role for the dorsomedial striatum during place learning. Studies in which rats are trained to use a place strategy rather than to choose between at least two different strategies may result in a stronger test of the hypothesis that activity in the dorsomedial striatum is related to place learning.

It is well established that formation of long-term memory is dependent on protein synthesis (Davis and Squire, 1984), and current theories of the cellular mechanisms of memory formation indicate that expression of c-Fos and the transcription of late-effector genes may stabilize synapses and increase synaptic efficacy to subsequent stimuli (Morgan and Curran, 1991). Transient synapse formation, for example, is related to CREB phosphorylation after avoidance learning (O'Connell et al., 2000). Reports of learning-induced CREB phosphorylation indicate that the time courses of peak phosphorylation may vary. For single-trial aversively motivated learning, CREB phosphorylation may be biphasic, with peaks immediately and 3-6 hr after training, but there is disagreement as to whether the immediate increase is caused by the aversive foot shock alone or the learned association (Bernabeu et al., 1997; Stanciu et al., 2002). In contrast to the biphasic peaks, Taubenfeld et al. (2001) reported that inhibitory avoidance training caused CREB phosphorylation that began immediately and was sustained for up to $20 \mathrm{hr}$ after training. Moreover, increased pCREB was reported $2 \mathrm{hr}$ after inhibitory avoidance training (Cammarota et al., 2000) and 1-2 hr after exposure to a novel environment (Vianna et al., 2000). For incremental learning in the radial arm maze, CREB phosphorylation reportedly is elevated after the last training trial on days 4 and 8 (Mizuno et al., 2002), which indicates that activity is either sustained or occurs in relation to each bout of learning. Learningrelated expression of c-Fos is generally reported to occur $1-2 \mathrm{hr}$ after training (Curran and Morgan, 1995; Stanciu et al., 2002). A recent study shows that c-Fos is expressed in the hippocampus during radial arm maze training, and that inhibition of c-Fos by antisense oligonucleotide treatment impairs spatial memory for- 

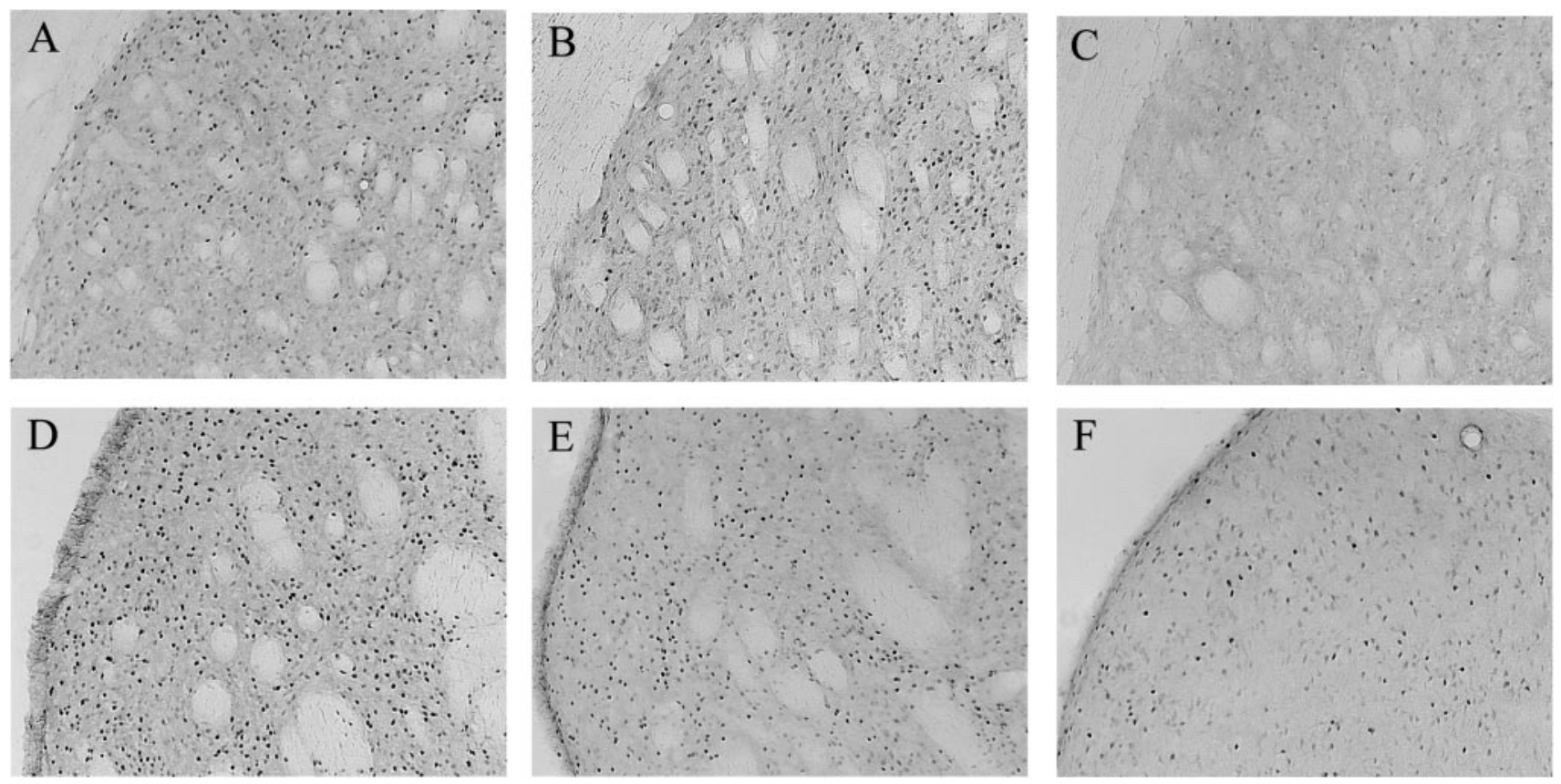

Figure 8. Representative $C-$ Fos-IR in the dorsolateral striatum of experimental $(A)$ and motor control $(B)$ rats immediately after training and experimental rats $(C) 1 \mathrm{hr}$ after training. Representative $c-F 0 s-I R$ in the dorsomedial striatum of experimental $(D)$ and motor control $(E)$ rats immediately after training and experimental rats $(F) 1 \mathrm{hr}$ after training.

mation (He et al., 2002). Sustained strategy- and region-specific activity of c-Fos and CREB $1 \mathrm{hr}$ after training, therefore, is in the range of previous reports of the time courses of learning-related activity of transcription factors. The present results indicate that pCREB is increased throughout the dorsal hippocampus of place learners $1 \mathrm{hr}$ after training, whereas c-Fos is expressed in CAl and the dentate gyrus but not in CA3. There is evidence that CA3 may be active during pattern completion rather than spatial learning because of recurrent connectivity (Kazu et al., 2002). It remains to be determined, however, whether the differences between c-Fos expression and CREB phosphorylation after cross maze training are attributable to differences in their time courses of maximal activity or to other factors.

As evidence for multiple memory systems increases, theorists are beginning to form hypotheses about how these systems interact in the intact brain. Multiple memory systems may act independently, cooperatively, competitively, or in temporal sequence (Packard and Knowlton, 2002; White and McDonald, 2002). The present findings support the view that the hippocampus and striatum can act in parallel during acquisition of a task that can be solved by either hippocampus- or striatum-dependent strategies. Additional studies of incremental learning may be necessary to reveal conditions under which the hippocampus and striatum may act competitively or in temporal sequence. The present results suggest further that localized, functional measurements of transcription factors and other signaling proteins during memory formation are useful for describing relationships among multiple memory systems during normal cognitive processes in the intact brain.

\section{References}

Bernabeu R, Bevilaqua L, Ardenghi P, Bromberg E, Schmitz P, Bianchin M, Izquierdo I, Medina JH (1997) Involvement of hippocampal cAMP/ cAMP-dependent protein kinase signaling pathways in a late memory consolidation phase of aversively motivated learning in rats. Proc Natl Acad Sci USA 94:7041-7046.

Bourtchuladze R, Frenguelli B, Blendy J, Cioffi D, Schutz G, Silva AJ (1994)
Deficient long-term memory in mice with a targeted mutation of the cAMP-responsive element-binding protein. Cell 79:59-68.

Brown HE, Garcia MM, Harlan RE (1998) A two focal plane method for digital quantification of nuclear immunoreactivity in large brain areas using NIH-image software. Brain Res Brain Res Protoc 2:264-272.

Cammarota M, Bevilaqua LR, Ardenghi P, Paratcha G, Levi DS, Izquierdo I, Medina JH (2000) Learning-associated activation of nuclear MAPK, CREB and Elk-1, along with Fos production, in the rat hippocampus after a one-trial avoidance learning: abolition by NMDA receptor blockade. Brain Res Mol Brain Res 76:36-46.

Casey BJ, Thomas KM, Davidson MC, Kunz K, Franzen PL (2002) Dissociating striatal and hippocampal function developmentally with a stimulus-response compatibility task. J Neurosci 22:8647-8652.

Colombo PJ, Davis HP, Volpe BT (1989) Allocentric spatial and tactile memory impairments in rats with dorsal caudate lesions are affected by preoperative behavioral training. Behav Neurosci 103:1242-1250.

Compton DM (2001) Are memories for stimulus-stimulus associations or stimulus-response associations responsible for serial-pattern learning in rats? Physiol Behav 72:643-652.

Curran T, Morgan JI (1995) Fos: an immediate-early transcription factor in neurons. J Neurobiol 26:403-412.

Dash PK, Karl KA, Colicos MA, Prywes R, Kandel ER (1991) cAMP response element-binding protein is activated by $\mathrm{Ca}^{2+} /$ calmodulin- as well as cAMPdependent protein kinase. Proc Natl Acad Sci USA 88:5061-5065.

Davis HP, Squire LR (1984) Protein synthesis and memory: a review. Psychol Bull 96:518-559.

DeCoteau WE, Kesner RP (2000) A double dissociation between the rat hippocampus and medial caudoputamen in processing two forms of knowledge. Behav Neurosci 114:1096-1108.

Devan BD, White NM (1999) Parallel information processing in the dorsal striatum: relation to hippocampal function. J Neurosci 19:2789-2798.

Devan BD, McDonald RJ, White NM (1999) Effects of medial and lateral caudate-putamen lesions on place- and cue-guided behaviors in the water maze: relation to thigmotaxis. Behav Brain Res 100:5-14.

Eichenbaum H (2001) The hippocampus and declarative memory: cognitive mechanisms and neural codes. Behav Brain Res 127:199-207.

Eichenbaum H, Stewart C, Morris RG (1990) Hippocampal representation in place learning. J Neurosci 10:3531-3542.

Fernandez-Ruiz J, Wang J, Aigner TG, Mishkin M (2001) Visual habit formation in monkeys with neurotoxic lesions of the ventrocaudal neostriatum. Proc Natl Acad Sci USA 98:4196-4201. 
Golf Racht-Delatour B, El Massioui N (1999) Rule-based learning impairment in rats with lesions to the dorsal striatum. Neurobiol Learn Mem 72:47-61.

Gonzalez GA, Montminy MR (1989) Cyclic AMP stimulates somatostatin gene transcription by phosphorylation of CREB at serine 133. Cell 59:675-680.

Guzowski JF, McGaugh JL (1997) Antisense oligodeoxynucleotide-mediated disruption of hippocampal cAMP response element binding protein levels impairs consolidation of memory for water maze training. Proc Natl Acad Sci USA 94:2693-2698.

He J, Yamada K, Nabeshima T (2002) A role of Fos expression in the CA3 region of the hippocampus in spatial memory formation in rats. Neuropsychopharmacology 26:259-268.

Josselyn SA, Shi C, Carlezon Jr WA, Neve RL, Nestler EJ, Davis M (2001) Long-term memory is facilitated by cAMP response element-binding protein overexpression in the amygdala. J Neurosci 21:2404-2412.

Kazu N, Quirk MC, Chitwood RA, Watanabe M, Yeckel MF, Sun LD, Kato A, Carr CA, Johnston D, Wilson MA, Tonegawa S (2002) Requirement for hippocampal CA3 NMDA receptors in associative memory recall. Science 297:211-218.

Kesner RP, Beers DR (1988) Dissociation of data-based and expectancybased memory following hippocampal lesions in rats. Behav Neural Biol 50:46-60.

Kesner RP, Bolland BL, Dakis M (1993) Memory for spatial locations, motor responses, and objects: triple dissociation among the hippocampus, caudate nucleus, and extrastriate visual cortex. Exp Brain Res 93:462-470.

Knowlton BJ, Mangels JA, Squire LR (1996) A neostriatal habit learning system in humans. Science 273:1399-1402.

Lamprecht R, Dudai Y (1996) Transient expression of c-Fos in rat amygdala during training is required for encoding conditioned taste aversion memory. Learn Mem 3:31-41.

Lamprecht R, Hazvi S, Dudai Y (1997) cAMP response element-binding protein in the amygdala is required for long- but not short-term conditioned taste aversion memory. J Neurosci 17:8443-8450.

Maguire EA, Burgess N, Donnett JG, Frackowiak RS, Frith CD, O'Keefe J (1998) Knowing where and getting there: a human navigation network. Science 280:921-924.

McDonald RJ, White NM (1993) A triple dissociation of memory systems: hippocampus, amygdala, and dorsal striatum. Behav Neurosci 107:3-22.

McDonald RJ, White NM (1994) Parallel information processing in the water maze: evidence for independent memory systems involving dorsal striatum and hippocampus. Behav Neural Biol 61:260-270.

Milanovic S, Radulovic J, Laban O, Stiedl O, Henn F, Spiess J (1998) Production of the Fos protein after contextual fear conditioning of C57BL/6N mice. Brain Res 784:37-47.

Mizuno M, Yamada K, Maekawa N, Saito K, Seishima M, Nabeshima T (2002) CREB phosphorylation as a molecular marker of memory processing in the hippocampus for spatial learning. Behav Brain Res 133:135-141.

Morgan JI, Curran T (1991) Stimulus-transcription coupling in the nervous system: involvement of the inducible proto-oncogenes fos and jun. Annu Rev Neurosci 14:421-451.

O’Connell C, Gallagher HC, O’Malley A, Bourke M, Regan CM (2000) CREB phosphorylation coincides with transient synapse formation in the rat hippocampal dentate gyrus following avoidance learning. Neural Plast 7:279-289.

Packard MG (1999) Glutamate infused posttraining into the hippocampus or caudate-putamen differentially strengthens place and response learning. Proc Natl Acad Sci USA 96:12881-12886.
Packard MG, Knowlton BJ (2002) Learning and memory functions of the basal ganglia. Annu Rev Neurosci 25:563-593.

Packard MG, McGaugh JL (1992) Double dissociation of fornix and caudate nucleus lesions on acquisition of two water maze tasks: further evidence for multiple memory systems. Behav Neurosci 106:439-446.

Packard MG, McGaugh JL (1996) Inactivation of hippocampus or caudate nucleus with lidocaine differentially affects expression of place and response learning. Neurobiol Learn Mem 65:65-72.

Packard MG, Teather LA (1997) Posttraining injections of MK-801 produce a time-dependent impairment of memory in two water maze tasks. Neurobiol Learn Mem 68:42-50.

Packard MG, Teather LA (1998) Amygdala modulation of multiple memory systems: hippocampus and caudate-putamen. Neurobiol Learn Mem 69:163-203.

Packard MG, White NM (1990) Lesions of the caudate nucleus selectively impair "reference memory" acquisition in the radial maze. Behav Neural Biol 53:39-50.

Packard MG, Cahill L, McGaugh JL (1994) Amygdala modulation of hippocampal-dependent and caudate nucleus-dependent memory processes. Proc Natl Acad Sci USA 91:8477-8481.

Qiang M, Xie J, Wang H, Qiao J (1999) Effect of nitric oxide synthesis inhibition on c-Fos expression in hippocampus and cerebral cortex following two forms of learning in rats: an immunohistochemistry study. Behav Pharmacol 10:215-222.

Radulovic J, Kammermeier J, Spiess J (1998) Relationship between fos production and classical fear conditioning: effects of novelty, latent inhibition, and unconditioned stimulus preexposure. J Neurosci 18:7452-7461.

Restle F (1957) Discrimination of cues in mazes: a resolution of the "placevs. response" question. Psychol Rev 64:217-227.

Sheng M, Greenberg ME (1990) The regulation and function of c-fos and other immediate early genes in the nervous system. Neuron 4:477-485.

Stanciu M, Radulovic J, Spiess J (2001) Phosphorylated cAMP response element binding protein in the mouse brain after fear conditioning: relationship to Fos production. Brain Res Mol Brain Res 94:15-24.

Taubenfeld SM, Wiig KA, Monti B, Dolan B, Pollonini G, Alberini CM (2001) Fornix-dependent induction of hippocampal CCAAT enhancerbinding protein $\beta$ and $\delta$ colocalizes with phosphorylated cAMP response element-binding protein and accompanies long-term memory consolidation. J Neurosci 21:84-91.

Teng E, Stefanacci L, Squire LR, Zola SM (2000) Contrasting effects on discrimination learning after hippocampal lesions and conjoint hippocampalcaudate lesions in monkeys. J Neurosci 20:3853-3863.

Tischmeyer W, Kaczmarek L, Strauss M, Jork R, Matthies H (1990) Accumulation of c-fos mRNA in rat hippocampus during acquisition of a brightness discrimination. Behav Neural Biol 54:165-171.

Vann SD, Brown MW, Erichsen JT, Aggleton JP (2000) Fos imaging reveals differential patterns of hippocampal and parahippocampal subfield activation in rats in response to different spatial memory tests. J Neurosci 20:2711-2718.

Vianna MR, Barros DM, Silva T, Choi H, Madche C, Rodrigues C, Medina JH, Izquierdo I (2000) Pharmacological demonstration of the differential involvement of protein kinase $\mathrm{C}$ isoforms in short- and long-term memory formation and retrieval of one-trial avoidance in rats. Psychopharmacology (Berl) 150:77-84.

Wan H, Aggleton JP, Brown MW (1999) Different contributions of the hippocampus and perirhinal cortex to recognition memory. J Neurosci 19:1142-1148.

White NM, McDonald RJ (2002) Multiple parallel memory systems in the brain of the rat. Neurobiol Learn Mem 77:125-184. 